\title{
Physical activity levels and sedentary time during school hours of 6th-grade girls in Germany
}

\author{
David J. Sturm ${ }^{1}$ (D) $\cdot$ Anne Kelso $^{1} \cdot$ Susanne Kobel ${ }^{2} \cdot$ Yolanda Demetriou $^{1}$ \\ Received: 30 September 2019 / Accepted: 22 December 2019 / Published online: 13 January 2020 \\ (C) The Author(s) 2020
}

\begin{abstract}
Aim Regular physical activity and low levels of sedentary time have positive health effects on youth, and data are needed to base public health recommendations on. Here, findings of device-based physical activity and sedentary time in sixth graders are presented. Data below are presented as mean (SD).

Subject and methods Three hundred and eight sixth-grade girls [11.6 (0.6) years] from the CReActivity study in Germany wore accelerometers (ActiGraph GT3X) for 7 consecutive days. Moderate to vigorous physical activity (MVPA), light physical activity (LPA), and sedentary time (ST) was obtained during school days with a focus on recess times.

Results Girls spent 79.9 (23.2) minutes in MVPA and 9.4 (1.2) hours in ST during schooldays, of which 20.5 (8.2) minutes and $3.8(0.4)$ hours respectively were accumulated during school hours. On average, students had 35.4 (4.5) minutes break, of which 6.3 (3.2) minutes (17.8\%) were spent in MVPA activity and 16.5 (6.2) minutes (46.6\%) in ST.

Conclusion School setting is an important factor for physical activity and sedentary time. Therefore policy, curriculums, and school environment should promote physical activity und reduce sedentary time during school hours.
\end{abstract}

Keywords Accelerometer $\cdot$ Adolescent $\cdot$ Moderate to vigorous activity (MVPA) $\cdot$ Secondary school $\cdot$ Break time

\section{Background}

Physical activity (PA) contributes to the development of the muscoskeletal and cardiovascular system, to neuromuscular control, and to the maintenance of healthy body weight and body composition (Poitras et al. 2016; WHO 2011). Additionally, PA is positively associated with psychological health and cognitive performance (Poitras et al. 2016). The World Health Organization (WHO) therefore recommends at least $60 \mathrm{~min}$ of daily moderate to vigorous physical activity (MVPA) for children and adolescents aged 5 to 17 years (WHO 2011). Since sedentary behaviours (SB) have been found to lead to adverse health outcomes in children and adolescents such as measures of obesity,

David J. Sturm

david.sturm@tum.de

1 Faculty of Sport and Health Sciences, Professorship of Educational Science in Sport and Health, Technical University of Munich, Uptown Munich - Campus D, Georg-Brauchle-Ring 60/62, 80992 Munich, Germany

2 Division of Sports and Rehabilitation Medicine, University Hospital Ulm, Frauensteige 6, Haus 58/33, 89075 Ulm, Germany lower cardiorespiratory fitness, and lower insulin sensitivity (Mitchell and Byun 2014; Tremblay et al. 2011b), the German activity guidelines recommend a minimum of 90 min MVPA per day. In addition, Pfeifer and Rütten (2017) incorporate a recommendation of maximum of 2 hours SB for children and adolescents between 6 and 18 years of age (Pfeifer and Rütten 2017). Nevertheless, PA levels of children and adolescents around the globe are low; the majority of adolescents do not meet the WHO activity guidelines, and girls are generally less active than boys (Hallal et al. 2012; Kalman et al. 2015; van Hecke et al. 2016). Based on self-reported PA data, $23.1 \%$ of boys and $14 \%$ of girls aged 11 to 15 years across Europe and North America engage in 60 min of daily MVPA (Kalman et al. 2015). In Germany, about $20 \%$ of girls and boys accumulate at least 60 min of MVPA per day, and the prevalence of SB of children and adolescents cannot be dismissed.

By definition, SB cannot be equated with screen time (Hoffmann et al. 2019), assuming that SB is characterized by a sitting or reclining posture with an energy expenditure of less than 1.5 METs (Metabolic Equivalent of Task) (Sedentary Behaviour Research Network 2012). However, Demetriou et al. (2019) reported that in Germany children and adolescents spend about $70 \%$ of their waking time in a sedentary position, of 
which a large share is accumulated by media consumption in front of a screen (Huber and Köppel 2017; Konstabel et al. 2014; Smith et al. 2016; Manz et al. 2014). Recommendations for SB suggest that children and adolescents should reduce unnecessary ST, and accumulate a maximum of two hours screen time during a day (Tremblay et al. 2011a; Pfeifer and Rütten 2017). In particular, limiting sedentary motorized transport, extended sitting time, and time spent indoors is recommended (Tremblay et al. 2011a). Although the school setting contributes to the aforementioned cases of SB (Smith et al. 2016; Bailey et al. 2012), an explicit recommendation for school time regarding SB is not yet available.

Nonetheless, the school setting provides numerous opportunities for students to be physically active (Ridgers et al. 2013). To ensure that children and adolescents meet current activity guidelines and benefit from the diverse health effects of PA, recommendations specifically for the school setting have been made. Both the USA and the UK recommend that students should accumulate a minimum of 30 min of MVPA during the school day (Department of Health 2016; Institute of Medicine 2013). Further, US guidelines recommend that students spend 30 to $45 \mathrm{~min}$ per day on average in Physical Education (PE) class, with half of the lesson time spent in MVPA; the remaining minutes of MVPA should be accrued during recess and classroom time devoted to PA (Institute of Medicine 2013). Additionally, at least $40 \%$ of recess time should be spent in MVPA (Ridgers et al. 2005).

Systematic reviews have described the correlates of PA behaviour of school-aged children and adolescents during break times (Ridgers et al. 2012), and examined the effectiveness of recess interventions on PA behaviour (Parrish et al. 2013; Ickes et al. 2013), yet there is a lack of information on students' actual activity levels and sedentary time (ST) during break times. Only a few original studies can provide some insight into students' PA levels during school break times. For example, Bailey et al. (2012) examined PA levels and ST in 10- to 14-year-old students during different segments of the school day and found that morning recess and lunch break accounted for $7 \%$ and $19.5 \%$ of daily MVPA respectively. Girls were less active and more sedentary than boys during both break times, and more boys than girls reached the recommended $40 \%$ of MVPA during recess $(60 \%$ and $28 \%$ respectively) and lunch break (64.9\% and $10.3 \%$ respectively) (Bailey et al. 2012). Ridgers et al. (2013) combined recess and lunchtime PA data of adolescents (14.1 (0.6) years) and found that students spent an average of $7.6 \%$ of their break time in MVPA compared to $39.4 \%$ in light PA and $52.9 \%$ being sedentary. Again, girls were more sedentary during break times than boys (Ridgers et al. 2013). Moreover, a decrease in PA participation during recess across the school grades 4 to 10 has been reported, together with a lower prevalence of girls being active during recess than boys across all school grades (Haug et al. 2010).
To date, only Kobel et al. (2015) have investigated the PA levels of German schoolchildren during recess in a sample of primary school children (7.1 (0.7) years), and found that recess accounted for nearly $7 \mathrm{~min}(5.8 \%)$ of daily MVPA and that boys accumulated significantly more minutes of MVPA during morning recess than girls.

These studies suggest that recess and lunch break can contribute, with varying proportions, to daily MVPA of schoolaged children and adolescents. Throughout the studies and investigated age groups, girls had lower PA levels than boys (Bailey et al. 2012; Haug et al. 2010; Kobel et al. 2015; Ridgers et al. 2013). However, differences in the methods used to determine PA as well as differences in the education systems (and allocated break times) between the studies limit their comparability.

Therefore, more studies are needed to develop a detailed understanding of children's and adolescents' PA behaviour during the school day and to develop effective interventions promoting PA levels and reducing ST during the school hours. The purpose of this study is to provide a further insight into PA levels and ST during school hours, with a special focus on activity levels during break times in a sample of sixth-grade girls located in the area of Munich, Germany.

\section{Methods}

\section{Participants}

Cross-sectional data of 308 sixth-grade female students participating in assessment wave 2 of the CReActivity project, a school-based intervention study aiming to promote girls' PA by supporting autonomy, relatedness, and competence in physical education (Demetriou and Bachner 2019a), were analysed. Girls aged 9 to 14 years [11.6 (0.6) years], from 11 secondary schools (Realschule) located in the Munich area of Germany formed this sub-sample. The sample size reduced due to failure or loss of PA assessment devices or insufficient wear time (WT) of the devices, resulting in invalid PA measurements. Two full-time classes with 28 students were excluded from the analysis because of deviations in school hours and school routines in comparison to the usual half-day school system in Bavaria, which determines school lessons from 8:00 a.m. to 1:00 pm with slight deviations in the starting time of school between 7:50 a.m. and 8:10 a.m. and in the finishing time of school between 12:55 a.m. and 1:15 p.m. In total, 254 sixth-grade students provided valid data for this analysis (see Fig. 1). 
Fig. 1 Flowchart of activity measurement procedure for the CReActivity study wave 2

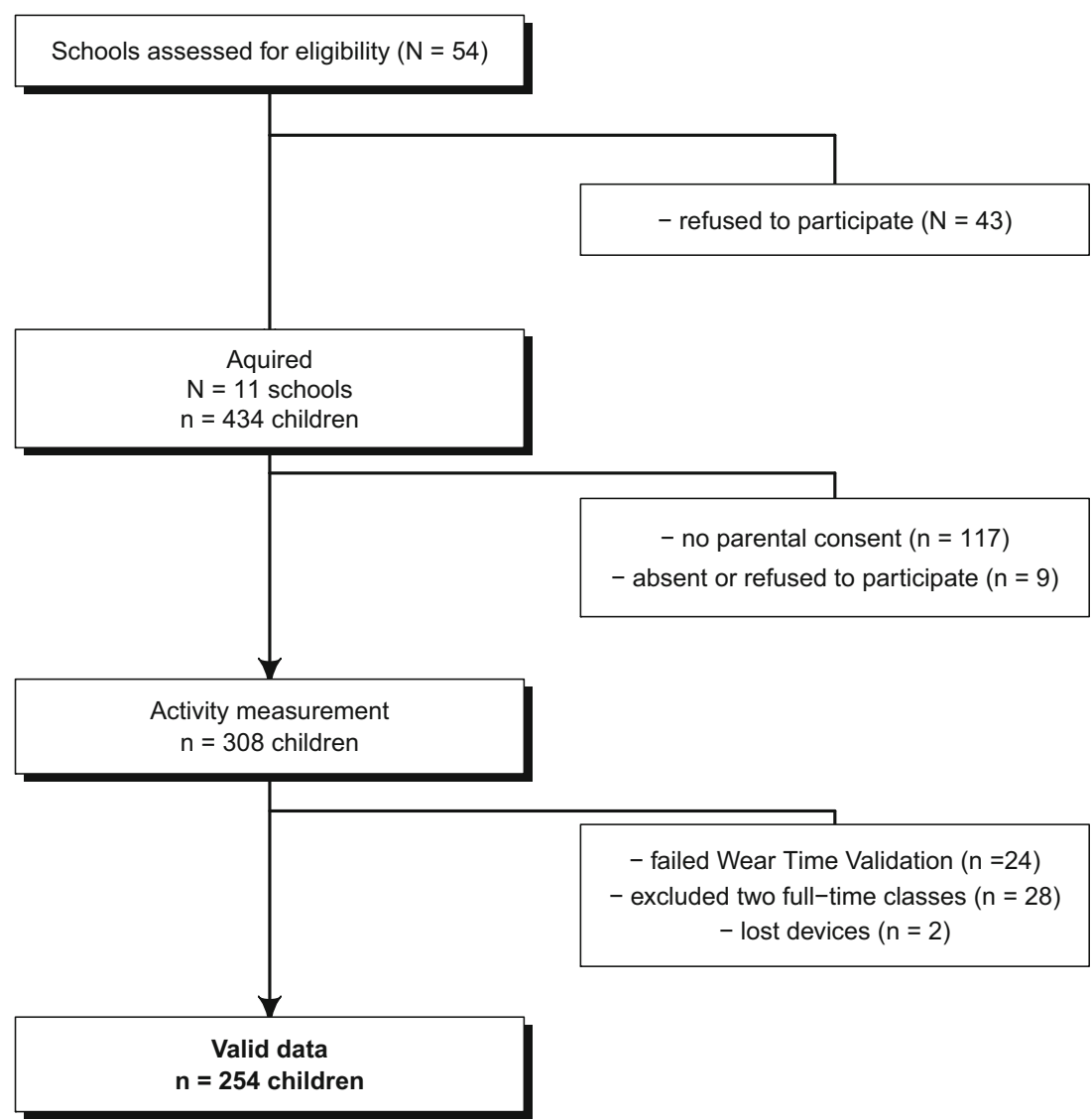

\section{Measurements}

\section{Physical activity and sedentary time measurement}

PA and ST were assessed using accelerometers (ActiGraph models GT3X - wGT3X-BT; Pensacola, FL, USA), which were attached on the right hip with an elastic belt. The participants were asked to wear the accelerometers for 7 consecutive days. On schooldays, students were advised to put on the devices in the morning after getting out of bed and wear them, except during water-based activities, until 9 p.m. or just before bedtime. Sampling rate was set to $30 \mathrm{~Hz}$ and has been described in detail previously (Demetriou and Bachner 2019b).

\section{Commuting to school}

Commute to school was assessed with two items, based on the validated MoMo-Physical Activity questionnaire (Schmidt et al. 2016). Two hundred and six of 278 participants answered the question "How do you usually get to school?" by marking one of the four possible answers: by foot, by bike, by public transport, by car. For the first two response options, the students were also requested to note down the number of minutes it took to get to school one-way, while for the third option only, the active walking time from home to station and from station to school was requested.

\section{Procedure}

The study was approved by the ethics commission of the Technical University of Munich, registered as 155/16S, and by the Ministry of Culture and Education of the state of Bavaria, Germany. Additionally, the school principals, parent's council, and the parents gave written informed consent to student's participation. A member of the research team explained how to put on the accelerometers and distributed the devices to all eligible students $(n=308)$ at the beginning of a school lesson. Afterwards, students completed the paper pencil questionnaire. After one week, the accelerometers were collected from the students (Demetriou and Bachner 2019b). The teachers reported morning breaks and school times of their classes. Data were collected in staggered time slots from October to December 2018.

\section{Data analysis}

After downloading the data from the device, vector magnitude counts from all three movement axes were calculated and pooled in 1-second epochs to describe the volatile activity behaviour of 
children (Baquet et al. 2007). Participants' accelerometer-based data were considered as valid if recorded data on at least 3 schooldays with at least 8 hours of WT were available. The algorithm of Choi et al. (2011) was used for the compliance check, since it effects a reasonable compromise with regard to remaining sample size and loss of information (Demetriou and Bachner 2019b). The first and the last day of assessment were excluded from the analysis to counteract novelty, and the last day had never more than 8 hours WT (Kobel et al. 2017). Moreover, school holidays were extracted from analysis. Activity levels were analysed using the cut points described by Hänggi et al. (2013) to calculate the average duration of ST $[<180$ counts per minute (cpm)], LPA (180-3360 cpm) and MVPA ( $\geq 3361 \mathrm{cpm})$. ActiLife v6.13.4 (ActiGraph 2019) was used for initialisation of accelerometers and the processing of the assessed data. In accordance with the aforementioned wearing guidelines, a school day was considered to be from 5 a.m. to 9 p.m., regular school time from 8 a.m. to 1 p.m. with respect to slight deviations, travel time $30 \mathrm{~min}$ before and after school time, and recess time as per the reported schedules of each class. PA analysis was considered for each individual separately for each time period. Descriptive statistics and illustrating graphs were performed using $\mathrm{R}$ ( $\mathrm{R}$ Development Core Team 2008). The proportion of girls fulfilling the PA recommendations was determined (WHO 2011; Department of Health 2016; Institute of Medicine 2013).

\section{Results}

Applying the above-mentioned criteria, $91.3 \%$ of the sample provided valid PA and ST data $(n=254$ of 278). Table 1 shows PA levels and ST of girls throughout different segments of the school day; $83.9 \%$ of girls fulfilled the global WHO guideline of 60 min MVPA per day. On a weekly average, the girls spent almost 80 (23.2) minutes per day in MVPA and 9.4 (1.2) hours in ST. During regular school time, those amounts decreased to 20.5 (8.2) minutes for MVPA and 3.8 (0.4) hours for ST daily. Mean duration of active travel time was 16.1 (12.0) minutes; therefore, $30 \mathrm{~min}$ before and after regular school time were assumed as travel time for students to and from school respectively. Including those time slots in the analysis, LPA level increased from 52.5 (15.0) to 68.0 (18.3) minutes and MVPA level from 20.5 (8.2) to 32.2 (10.6) minutes.

Figure 2 shows average activity behaviour during school time. ST is high during lesson times, while higher amounts of MVPA and LPA before and after school time as well as in recess are recognisable. A detailed evaluation of break times showed that the morning breaks took place in two time slots from 09:20 10:00 a.m. and 11:10-11:45 a.m., with a duration of 10 to $20 \mathrm{~min}$. While break 1 had a mean of 17.4 (3.7) minutes, break 2 was on average 18.0 (2.5) minutes long. Girls spent $46.6 \%$ of their recess time being sedentary (see Fig. 3). Combining both break times [35.4 (4.5) minutes], girls spent $17.8 \%$ of their average break in MVPA. Those 6.3 (3.2) minutes in MVPA accounted for an average of $8.0 \%$ of daily MVPA. Also shown in Table 2, the majority of participants did not meet the guidelines for MVPA during school times (Department of Health 2016; Institute of Medicine 2013).

\section{Discussion}

This study provides an overview of device-based assessed PA levels and ST of sixth-grade girls during different segments of the school day. The results underpin the assumption that school plays an important role in PA engagement on a regular weekday, and in particular that the commute to and from school and morning breaks are key sources for school-related PA. ST was most prevalent during lesson hours, but also accounted for the largest proportion of recess time.

Within a day, 60 min of MVPA are required to fulfill the global recommendation (WHO 2011). The results suggest that the majority of girls in this study sample are being more active than the WHO recommends. Demetriou and Bachner (2019b) analysed the activity of sixth-grade girls in southern Germany ( $n=482$ ), including the CReActivity sample, and stated that $90 \%$ of the girls fulfill the WHO recommendation. As mentioned before, analysis methods were similar to this analysis; both used
Table 1 ST and PA behaviour in minutes [mean (standard deviation)] throughout the school day and during different segments of the school day

\begin{tabular}{lllll}
\hline & $\begin{array}{l}\text { School day (5 a.m.- } \\
9 \text { p.m.) }\end{array}$ & $\begin{array}{l}\text { Regular school } \\
\text { time + travel time }\end{array}$ & $\begin{array}{l}\text { Regular school time } \\
(8 \text { a.m. }-1 \text { p.m. })\end{array}$ & Recess \\
\hline ST/day & $561.93(70.56)$ & $255.09(34.68)$ & $226.95(25.83)$ & $16.50(6.16)$ \\
LPA/day & $152.82(33.82)$ & $68.04(18.32)$ & $52.46(14.95)$ & $11.10(4.01)$ \\
MVPA/day & $79.94(23.23)$ & $32.17(10.59)$ & $20.49(8.24)$ & $6.29(3.21)$ \\
VMCPM & $767.05(215.24)$ & $667.14(209.84)$ & $544.36(216.81)$ & 1400.84 \\
WT/day & $794.69(75.42)$ & $355.41(38.39)$ & $299.98(23.68)$ & $33.90(3.86)$ \\
\hline
\end{tabular}

ST sedentary time, LPA light physical activity, MVPA moderate to vigorous physical activity, VMCPM vector magnitude counts per min, $W T$ wear time on valid days

a including recess 


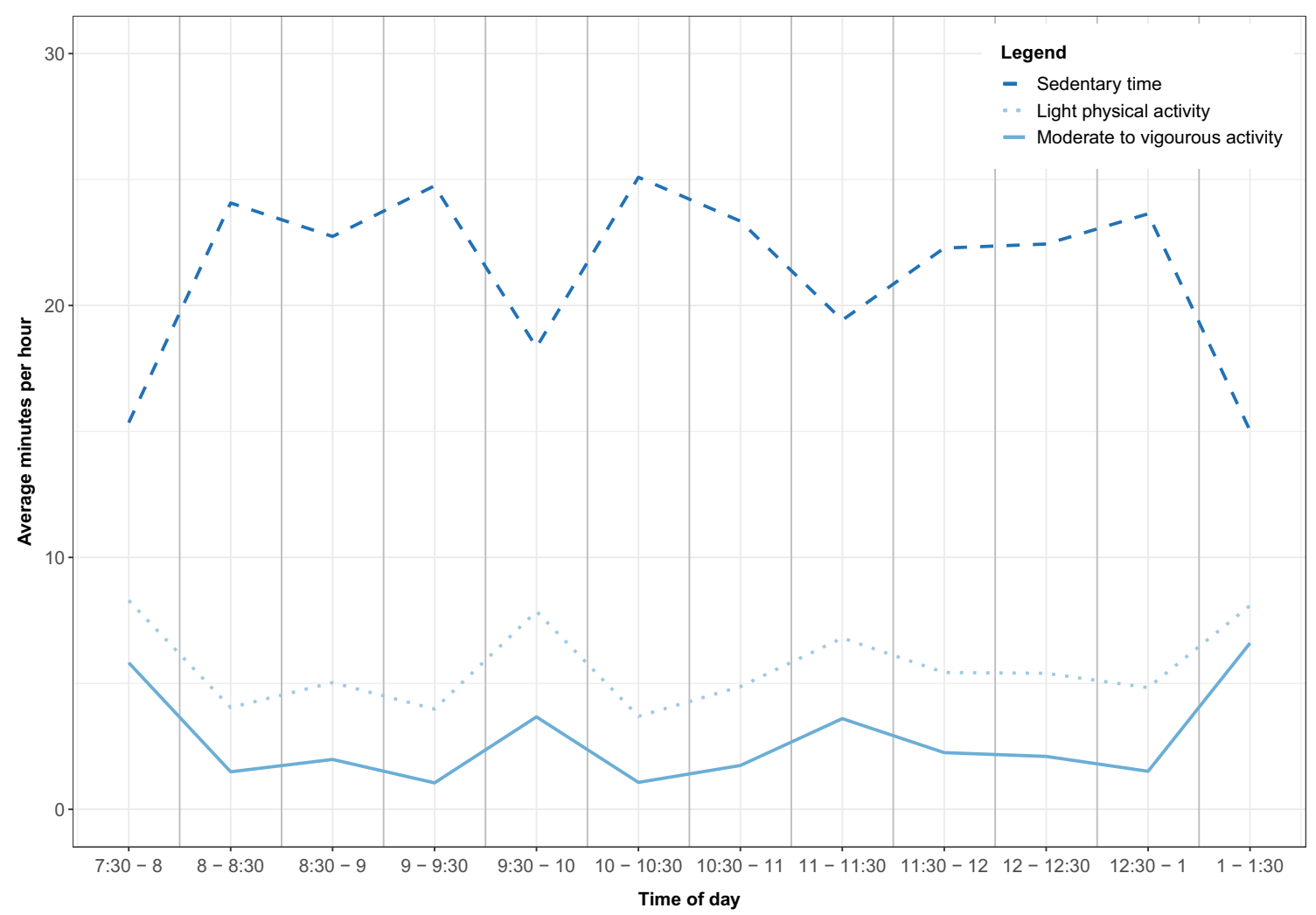

Fig. 2 Activity behaviour during school time

the relatively high cut-off points of Hänggi et al. (2013), and showed that the proportion of students fulfilling the WHO recommendation is large. However, Troiano et al. (2014) stated that the comparison of these guidelines with device-based assessed data has to be interpreted carefully, because the WHO guidelines were developed on the basis of self-reported PA behaviour (Troiano et al. 2014), and both measurement methods could over- or underestimate PA and ST due to varieties in validity. Furthermore, results of accelerometry data depend on the methodological decisions made under consideration of age, gender, and setting (Guinhouya et al. 2013). Although Migueles et al. (2017) provide good indications, a best practice to process and analyse such data is not yet available. However, the comparison of outcomes with other studies is limited, because of the scientific

Fig. 3 Activity behaviour during recess

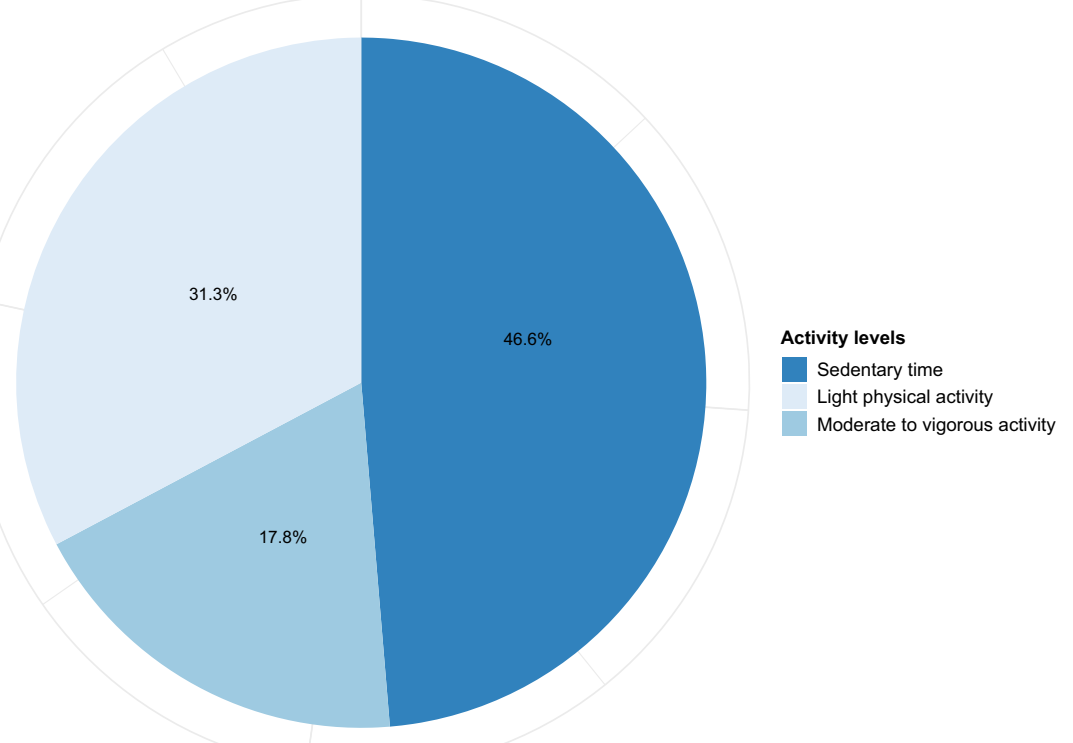


Table 2 Proportion of girls fulfilling global guidelines for MVPA during school hours and recess

\begin{tabular}{llcl}
\hline Guideline & Time & Proportion & Reference \\
\hline$\geq 30$ min MVPA & Regular school time & $11.02 \%$ & $\begin{array}{c}\text { Institute of Medicine (2013), } \\
\text { Department of Health (2016) }\end{array}$ \\
$\geq 60$ min MVPA & School day & $83.86 \%$ & WHO (2011) \\
$\geq 40 \%$ of recess in MVPA & Morning break times combined & $2.76 \%$ & Ridgers et al. (2005) \\
\hline
\end{tabular}

MVPA moderate to vigorous physical activity, WHO World Health Organization decisions on processing the data (Guinhouya et al. 2013), and are not the subject of this discussion. Instead, we refer to Demetriou and Bachner (2019b) and continue with the results regarding PA during school time and recess.

Further, there is the possibility that the MVPA recommendations of 30 min during school time in the USA and UK (Department of Health 2016; Institute of Medicine 2013), may not be applicable to the half-day school systems in Germany. Since there is no national recommendation available for MVPA during school time, this recommendation was used as a reference point. The obvious difference in MVPA during school time between Bailey's et al. (2012) full-time students and the students in this sample implies discrepancies in their daily activity behaviour. In this study, girls' school time accounted for an average of $20.5 \mathrm{~min}$ of MVPA, which is one quarter of their daily MVPA. In comparison to longer school times, the sample of Bailey et al. (2012) accrued 35.3\% of their daily MVPA in school. In both studies, the majority of daily MVPA was accumulated outside school hours, of which a considerable share is still school-related. One should consider that travel to school contributes to the daily MVPA level with $10 \%$ (Bailey et al. 2012), 14\% (Smith et al. 2016), and 15\% in this study sample. Hence, school travel is an opportunity for all pupils to be physically active during the school day, but within daily school life PA levels are negatively influenced by another distinct health factor (Thivel et al. 2018; Tremblay et al. 2011b).

Moreover, three-quarters of school time was spent in ST. As other studies have shown, the school setting accounts for high ST (Bailey et al. 2012; Smith et al. 2016; Sprengeler et al. 2017), and girls in this study spent $3 \mathrm{~h}$ and $30 \mathrm{~min}$ sedentary during lesson hours. Huber and Köppel (2017) reported even $4.9 \mathrm{~h}$ of school-related ST across all grades. Evidently, schoolrelated sitting is dominant (Demetriou et al. 2019), but also leisure time accounts for additional ST, with the result that $9.4 \mathrm{~h}$ in this sample and $10.6 \mathrm{~h}$ in Huber and Köppels' (2017) sample of 4- to 20-year-olds were spent in a sedentary position. Referring to Hoffmann et al. (2017), sample primary students are less sedentary, with $3.7 \mathrm{~h}$ ST on schooldays than secondary female students in UK, with $6.2 \mathrm{~h} \mathrm{ST} \mathrm{(Bailey} \mathrm{et} \mathrm{al.}$ 2012). Self-reported data of numerous studies hold media consumption (e.g., screen time) to be accountable for high SB (Manz et al. 2014; Bucksch and Dreger 2014; Konstabel et al. 2014). This clearly illustrates the indistinctive terminologies with regard to SB in literature (Graf et al. 2014). But in summary, it can be said that school should educate students towards an active healthy lifestyle and a meaningful and responsible handling of media to overcome sedentariness (Strasburger 2010).

The data indicate that this task could be accomplished. Girls spent more than 40 min of lesson hours in LPA. This shows that during regular lessons at least light activities can be performed, e.g., walking to the next classroom in transition times, or by means of active teaching methods. However, ST was high during lesson time and it seems that most of the girls do not compensate for this by an intense activity during break time. Not even $3 \%$ of the sample meet the MVPA guideline for break times (Ridgers et al. 2005). Girls of this study accrued more than 6 min in MVPA during break times, which is less than $18 \%$ of the average break time. In comparison, primary school girls in Germany spent an average of $20.4 \%$ of their break times in MVPA (Kobel et al. 2015). In accordance with previous research, the guideline of $40 \%$ of MVPA during break times appears to be a high threshold for girls. In the UK, $28.2 \%$ of 10-14-year-old girls (Bailey et al. 2012), and only $4.3 \%$ in a sample of younger girls met the guideline.

In order to understand these low MVPA levels future research should incorporate social and individual factors, such as social support and individual motivational attitudes towards PA. Equivalent to 3-6 METs, MVPA causes rapid breathing and substantial increase in heart rate (Thivel et al. 2018); and therefore, after occurrence of thermoregulatory processes, perspiration. This could be a reason for adolescent girls to engage less in exhausting and intensive activities during recess, because they do not want to attend class with wet or dirty clothes afterwards. The result is a high proportion of ST (46.6\%) and LPA (31.3\%) during recess which is consistent with findings of other studies, with $52.9 \%$ in ST and 39.4\% in LPA respectively (Ridgers et al. 2013). In comparison to lesson time, the girls are more active during recess and accumulate $8 \%$ of daily MVPA, which is similar to findings from other studies (Kobel et al. 2017; Bailey et al. 2012), but amounts of low PA and ST are too high in both segments.

Reduced sitting time would diminish the salient amounts of SB during school time, and comes along with increased PA levels. Facing the aforementioned reasons of low MVPA levels of girls during school time, it could be a future objective of interventions to target the incorporation of low-intensity activities, such as standing, walking, etc., in non-PE classes, to increase the LPA amounts of girls during lesson time as well as in recess to accomplish the national and global recommendations for PA 
(Pfeifer and Rütten 2017; WHO 2011). Therefore, classroom teachers should be provided with class-related material and knowledge to enhance the active interruption of long ST periods and to diminish the total ST of children.

The major strength of this study is the detailed insight into device-based assessed PA and ST behaviour during school time of secondary school girls. As the second of its type in Germany, this study expands the status quo of PA and ST of students due to its detailed analysis of a large sample size and the disclosure of methodological decisions, which establishes a foundation for further investigations in the school setting.

This study has several limitations. Mediating factors of PA and ST, such as seasonal variability and environmental factors, were not considered in the analysis. Although studies showed that seasonal effects were not seen as important factor for PA during recess (Ridgers et al. 2006), a weather-related effect could have influenced the girls' PA engagement during the school day, since assessments were conducted in autumn and beginning of winter (Atkin et al. 2016). Cleary evident is the association of body weight with PA (Kobel et al. 2015), but anthropometric data were assessed later during the study and were not available for this analysis. For unstructured times, such as recess, travel time and leisure time, no further information was given about contextual factors, such as school route, school environment, and neighborhood. Furthermore, school policies and characteristics, such as active breaks and activity-supportive profiles were not controlled for. Schoolyard size was not determined, yet several studies showed inconclusive results with regard to the effects of playground size on PA behaviour during recess (Kobel et al. 2015). Because girls were monitored by an accelerometer, it is possible that they behaved more actively as usual during wearing periods.

\section{Conclusion}

The findings of this study provide further insight into a girl's PA behaviour during a regular weekday by providing detailed information on PA levels and ST during regular school time, the travel to school, and school break times. The results with regard to the fulfillment of global activity guidelines reinforce the need of two important issues: a) a consistent procedure for processing and analysis of accelerometer data, and b) national guidelines for PA and ST during school time. Mentioning this, it will be the task for researchers to raise teachers' and pupils' awareness towards the idea that school is not only an academic institution but also an activity environment.

Acknowledgments We thank all schools, teachers, and students who participated in this study. Furthermore, special thanks goes to our research assistants, who collected data and put a lot of effort into our project. We gratefully acknowledge the support of the Deutsche Forschungsgemeinschaft, Germany. The views expressed are those of the authors and not necessarily those of the Deutsche Forschungsgemeinschaft.
Author contribution Conceptualization: Yolanda Demetriou, David Sturm. Methodology: David Sturm, Susanne Kobel. Formal analysis and investigation: David Sturm. Writing - original draft preparation: Anne Kelso, David Sturm. Writing - review and editing: Yolanda Demetriou, Susanne Kobel, Anne Kelso, David Sturm. Funding acquisition: Yolanda Demetriou. Supervision: Yolanda Demetriou.

Funding information Open Access funding provided by Projekt DEAL. The Deutsche Forschungsgemeinschaft (DE 2680/3-1) funds the study. The researchers are independent of the funders who have no influence on study design, conduct, analyses, or interpretation of the data, or decision to submit results. The funding body did not take part in the design of the study, the collection, analysis, and interpretation of data, and preparation of the manuscript. German Clinical Trials Register DRKS00015723 (date of registration: 2018/10/22 retrospectively registered).

\section{Compliance with ethical standards}

Conflict of interest The authors declare that they have no conflict of interest.

Ethical statement This material is the authors' own original work, which has not been previously published elsewhere. The paper is not currently being considered for publication elsewhere. The paper reflects the authors' own research and analysis in a truthful and complete manner. The paper properly credits the meaningful contributions of co-authors and co-researchers. The results are appropriately placed in the context of prior and existing research. All sources used are properly disclosed (correct citation). All authors have been personally and actively involved in substantial work leading to the paper, and will take public responsibility for its content.

Open Access This article is licensed under a Creative Commons Attribution 4.0 International License, which permits use, sharing, adaptation, distribution and reproduction in any medium or format, as long as you give appropriate credit to the original author(s) and the source, provide a link to the Creative Commons licence, and indicate if changes were made. The images or other third party material in this article are included in the article's Creative Commons licence, unless indicated otherwise in a credit line to the material. If material is not included in the article's Creative Commons licence and your intended use is not permitted by statutory regulation or exceeds the permitted use, you will need to obtain permission directly from the copyright holder. To view a copy of this licence, visit http://creativecommons.org/licenses/by/4.0/.

\section{References}

ActiGraph LLC (2019) ActiLife. ActiGraph, LLC, Pensacola

Atkin AJ, Sharp SJ, Harrison F, Brage S, van Sluijs EMF (2016) Seasonal variation in children's physical activity and sedentary time. Med Sci Sports Exerc 48(3):449-456

Bailey DP, Fairclough SJ, Savory LA, Denton SJ, Pang D, Deane CS, Kerr CJ (2012) Accelerometry-assessed sedentary behaviour and physical activity levels during the segmented school day in 10-14year-old children: the HAPPY study. Eur J Pediatr 171:1805-1813

Baquet G, Stratton G, van Praagh E, Berthoin S (2007) Improving physical activity assessment in prepubertal children with high-frequency accelerometry monitoring: a methodological issue. Prev Med 44:143-147

Bucksch J, Dreger S (2014) Sitzendes Verhalten als Risikofaktor im Kindes- und Jugendalter. Präv Gesundheitsf 9(1):39-46 
Choi L, Liu Z, Matthews CE, Buchowski MS (2011) Validation of accelerometer wear and nonwear time classification algorithm. Med Sci Sports Exerc 43(2):357-364

Demetriou Y, Bachner J (2019a) A school-based intervention based on self-determination theory to promote girls' physical activity: study protocol of the CReActivity cluster randomised controlled trial. BMC Public Health 19(1):519

Demetriou Y, Bachner J (2019b) Objective levels and patterns of physical activity and sedentary time in sixth graders in southern Germany. PLoS One [under review]

Demetriou Y, Bucksch J, Antje H, Schlund A, Niessner C, Schmidt S, Finger J, Mutz M, Völker K, Vogt L, Woll A, Reimers A (2019) Germany's 2018 report card on physical activity for children and youth. German Journal of Exercise and Sport Research 49:113-126

Department of Health (2016) Childhood obesity: a plan for action. Department of Health and Social Care, London

Graf C, Beneke R, Bloch W, Bucksch J, Dordel S, Eiser S, Ferrari N, Koch B, Krug S, Lawrenz W, Manz K, Naul R, Oberhoffer R, Quilling E, Schulz H, Stemper T, Stibbe G, Tokarski W, Völker K, Woll A (2014) Recommendations for promoting physical activity for children and adolescents in Germany. A consensus statement. Obes Facts 7(3):178-190

Guinhouya BC, Samouda H, Beaufort C (2013) Level of physical activity among children and adolescents in Europe: a review of physical activity assessed objectively by accelerometry. Public Health 127:301-311

Hallal PC, Andersen LB, Bull FC, Guthold R, Haskell W, Ekelund U (2012) Global physical activity levels: surveillance progress, pitfalls, and prospects. Lancet 380(9838):247-257

Hänggi JM, Phillips LRS, Rowlands AV (2013) Validation of the GT3X ActiGraph in children and comparison with the GT1M ActiGraph. J Sci Med Sport 16(1):40-44

Haug E, Torsheim T, Sallis JF, Samdal O (2010) The characteristics of the outdoor school environment associated with physical activity. Health Educ Res 25(2):248-256

Hoffmann B, Kettner S, Wirt T, Wartha O, Hermeling L, Steinacker JM, Kobel S (2017) Sedentary time among primary school children in south-West Germany: amounts and correlates. Archives of Public Health $=$ Archives belges de santé publique 75:63

Hoffmann B, Kobel S, Wartha O, Kettner S, Dreyhaupt J, Steinacker JM (2019) High sedentary time in children is not only due to screen media use: A cross-sectional study. BMC Pediatrics, 19(1):154. https://doi.org/10.1186/s12887-019-1521-8

Huber G, Köppel M (2017) Analyse der Sitzzeiten von Kindern und Jugendlichen zwischen 4 und 20 Jahren. DZSM 2017(04):101-106

Ickes MJ, Erwin H, Beighle A (2013) Systematic review of recess interventions to increase physical activity. J Phys Act Health 10(6):910-926

Institute of Medicine (ed) (2013) Educating the student body: taking physical activity and physical education to school. National Academies Press, Washington, DC

Kalman M, Inchley J, Sigmundova D, Iannotti RJ, Tynjala JA, Hamrik Z, Haug E, Bucksch J (2015) Secular trends in moderate-to-vigorous physical activity in 32 countries from 2002 to 2010: a cross-national perspective. Eur J Pub Health 25(2):37-40

Kobel S, Kettner S, Erkelenz N, Kesztyüs D, Steinacker JM (2015) Does a higher incidence of break times in primary schools result in children being more physically active? J Sch Health 85:149-154

Kobel S, Kettner S, Lämmle C, Steinacker JM (2017) Physical activity of German children during different segments of the school day. J Public Health 25(1):29-35

Konstabel K, Veidebaum T, Verbestel V, Moreno LA, Bammann K, Tornaritis M, Eiben G, Molnár D, Siani A, Sprengeler O, Wirsik N, Ahrens W, Pitsiladis Y (2014) Objectively measured physical activity in European children: the IDEFICS study. Int J Obes 38(2):135-143

Manz K, Schlack R, Poethko-Müller C, Mensink G, Finger J, Lampert T (2014) Körperlich-sportliche Aktivität und Nutzung elektronischer Medien im Kindes- und Jugendalter Ergebnisse der KiGGS-Studie -
Erste Folgebefragung (KiGGS Welle 1). Bundesgesundheitsblatt, Gesundheitsforschung, Gesundheitsschutz 57(7):840-848

Migueles JH, Cadenas-Sanchez C, Ekelund U, Delisle Nyström C, MoraGonzalez J, Löf M, Labayen I, Ruiz JR, Ortega FB (2017) Accelerometer data collection and processing criteria to assess physical activity and other outcomes: a systematic review and practical considerations. Sports Med 47(9):1821-1845

Mitchell JA, Byun W (2014) Sedentary behavior and health outcomes in children and adolescents. Am J Lifestyle Med 8(3):173-199

Parrish A-M, Okely AD, Stanley RM, Ridgers ND (2013) The effect of school recess interventions on physical activity a systematic review. Sports Med 43(4):287-299

Pfeifer K, Rütten A (2017) Nationale Empfehlungen für Bewegung und Bewegungsförderung. Gesundheitswesen (Bundesverband der Arzte des öffentlichen Gesundheitsdienstes (Germany)) 79(1):2-3

Poitras VJ, Gray CE, Borghese MM, Carson V, Chaput J-P, Janssen I, Katzmarzyk PT, Pate RR, Connor Gorber S, Kho ME, Sampson M, Tremblay MS (2016) Systematic review of the relationships between objectively measured physical activity and health indicators in schoolaged children and youth. Applied Physiology, Nutrition, and Metabolism = Physiologie appliquée, nutrition et métabolisme 41(6):197-239

R Development Core Team (2008) R: a language and environment for statistical computing. R Foundation for Statistical Computing, Vienna

Ridgers ND, Stratton G, Fairclough SJ (2005) Assessing physical activity during recess using accelerometry. Prev Med 41(1):102-107

Ridgers ND, Stratton G, Clark E, Fairclough SJ, Richardson DJ (2006) Day-to-day and seasonal variability of physical activity during school recess. Prev Med 42(5):372-374

Ridgers ND, Salmon J, Parrish A-M, Stanley RM, Okely AD (2012) Physical activity during school recess: a systematic review. Am J Prev Med 43(3):320-328

Ridgers ND, Timperio A, Crawford D, Salmon J (2013) What factors are associated with adolescents' school break time physical activity and sedentary time? PLoS One 8(2):e56838

Schmidt S, Will N, Henn A, Reimers A, Woll A (2016) Der MotorikModul Aktivitätsfragebogen MoMo-AFB Leitfaden zur Anwendung und Auswertung. KIT, Karlsruhe

Sedentary Behaviour Research Network (2012) Letter to the editor: standardized use of the terms "sedentary" and "sedentary behaviours". Applied Physiology, Nutrition, and Metabolism = Physiologie appliquée, nutrition et métabolisme 37(3):540-542

Smith MP, Berdel D, Nowak D, Heinrich J, Schulz H (2016) Physical activity levels and domains assessed by Accelerometry in German adolescents from GINIplus and LISAplus. PLoS One 11(3):e0152217

Sprengeler O, Wirsik N, Hebestreit A, Herrmann D, Ahrens W (2017) Domain-specific self-reported and objectively measured physical activity in children. Int J Environ Res Public Health 14(3):pii: E242

Strasburger VC (2010) Media education. Pediatrics 126(5):1012-1017

Thivel D, Tremblay A, Genin PM, Panahi S, Rivière D, Duclos M (2018) Physical activity, inactivity, and sedentary behaviors: definitions and implications in occupational health. Front Public Health 6:288

Tremblay MS, LeBlanc AG, Janssen I, Kho ME, Hicks A, Murumets K, Colley RC, Duggan M (2011a) Canadian sedentary behaviour guidelines for children and youth. Applied Physiology Nutrition, and Metabolism = Physiologie appliquée, nutrition et métabolisme 36(1):59-64 65-71

Tremblay MS, LeBlanc AG, Kho ME, Saunders TJ, Larouche R, Colley RC, Goldfield G, Connor Gorber S (2011b) Systematic review of sedentary behaviour and health indicators in school-aged children and youth. Int J Behav Nutr Phys Act 8:98

Troiano RP, McClain JJ, Brychta RJ, Chen KY (2014) Evolution of accelerometer methods for physical activity research. Br J Sports Med 48(13):1019-1023

van Hecke L, Loyen A, Verloigne M, van der Ploeg HP, Lakerveld J, Brug J, de Bourdeaudhuij I, Ekelund U, Donnelly A, Hendriksen I, Deforche B (2016) Variation in population levels of physical activity in European 
children and adolescents according to cross-European studies: a systematic literature review within DEDIPAC. Int J Behav Nutr Phys Act 13:70

WHO (2011) Global Recommendations on Physical Activity for Health:

5-17 years old. WHO, Geneva. http://www.who.int/ dietphysicalactivity/pa/en/index.html. Accessed 08 July 2019
Publisher's note Springer Nature remains neutral with regard to jurisdictional claims in published maps and institutional affiliations. 